\title{
Labyrinthe
}

21 | 2005 (2)

Communauté en pièces : d'Europe, d'Islam et d'ailleurs

\section{Sciences sociales : définitions et traditions}

\section{(2) OpenEdition}

1 Journals

Édition électronique

URL : http://journals.openedition.org/labyrinthe/901

DOI : 10.4000/labyrinthe.901

ISSN : 1950-6031

Éditeur

Hermann

Édition imprimée

Date de publication : 22 juin 2005

Pagination : 47-48

Référence électronique

"Sciences sociales : définitions et traditions », Labyrinthe [En ligne], 21 | 2005 (2), mis en ligne le 10 juillet 2008, consulté le 01 mai 2019. URL : http://journals.openedition.org/labyrinthe/901 ; DOI :

10.4000/labyrinthe.901

Propriété intellectuelle 


\section{Sciences sociales: définitions et traditions}

- « Communauté : groupe non choisi auquel l'individu délègue de manière automatique, globale et irréversible sa compétence et son action stratégiques.

Le terme "communauté" possède plusieurs acceptions. II peut signifier une simple association, c'est-à-dire une mise en commun partielle ("Communauté des États indépendants") ; il peut aussi indiquer une collectivité à solidarité conditionnelle, volontaire et réversible ("communauté scientifique"), comme en anglais, où, surtout en Amérique du Nord, "community" peut parfois prendre ce sens faible et désigner un quartier ou une société locale ; le mot peut encore se référer à une société en tant qu'elle fonctionne comme un tout, comme on le voit dans l'expression "communauté politique", équivalent de "société politique". II apparaît cependant utile de spécialiser ce terme, dans l'esprit des sciences sociales allemandes et françaises du début du $x x^{e}$ siècle. On reprend alors l'opposition Gemeinschaft/Gesellschaft proposée par Ferdinand Tönnies dans le couple mécanique/organique d'Émile Durkheim. Max Weber, Georg Simmel, Karl von Polanyi ou plus tard Louis Dumont disent des choses comparables sur ce point. [...] Norbert Elias a donné une cohérence lexicale accrue à cette dualité en nommant la Gesellschaft "société des individus" par opposition à une société communautaire (Gemeinschaft). Dans ce couple se manifeste le repérage de la "grande transformation" qui trouve ses prémisses dans l'Europe médiévale et qui se déploie progressivement durant les trois derniers siècles. Les auteurs divergent parfois sur la question de savoir jusqu'à quel point le monde contemporain s'est décommunautarisé ainsi que sur la puissance des individus comme acteurs face aux acteurs collectifs ou institutionnels ${ }^{2}$. »

1. Référence à Karl Polanyi, La Grande Transformation. Aux origines politiques et économiques de notre temps, Paris, NRF-Gallimard, coll. "Bibliothèque des sciences humaines », 1983 [éd. orig. 1944-1972].

2. Extrait de Jacques Lévy, article "Communauté », dans Jacques Lévy, Michel Lussault (dir.), Dictionnaire de la géographie et de l'espace des sociétés, Paris, Belin, 2004, p. 177. L'auteur renvoie notamment à Norbert Elias, La Société des individus, Paris, Fayard, 1991, et à Ferdinand Tönnies, Communauté et Société. Catégories fondamentales de la sociologie pure, Paris, Puf, 1944 (éd. orig. 1887). Voir aussi, dans le même dictionnaire, l'article «Communauté/Société » (p. 178-180). 
- La « communauté » des sciences sociales est donc un groupe relativement endogame, partageant des valeurs culturelles relativement uniformisées, constituant un champ d'interaction dense, distinct des groupes environnants, organisé socialement, culturellement et juridiquement ; il n'est pas rare que la religion soit considérée comme son marqueur ultime ${ }^{3}$.

- Un emploi du terme «communauté » peut, à l'instar de ce que propose Hamit Bozarslan, désigner un groupe qui se singularise par certaines caractéristiques "essentialisables» (ancêtre commun, confession, langue, style de vie, références historiques spécifiques...). En ce sens, le concept ne signifie pas l'isolement ou l'immuabilité des conditions d'un groupe donné; au contraire, on ne constitue une communauté que si l'on se trouve en interaction avec d'autres groupes et si l'on négocie ses distances et ses proximités avec eux. En règle générale, les frontières qui séparent plusieurs communautés restent fluides, l'espace de non-mixité étant réduit à quelques domaines (domaine matrimonial, lieux et rituels du culte...). Lors des crises cependant, ces frontières peuvent gagner un sens étymologique du terme, élargissant alors considérablement l'espace de non-mixité ${ }^{4}$.

3. Fred W. Riggs (dir.), Ethnicity : Intercocta Glossary, Honolulu, University of Hawaï, 1985, p. 121-122, cité par Élisabeth Picard, «De la domination du groupe à l'invention de son identité. Les milices libanaises et les paramilitaires nord-irlandais ", dans Denis-Constant Martin (dir.), Cartes d'identité. Comment dit-on «nous» en politique?, Paris, Presses de Sciences-po, 1994, p. 147.

4. Hamit Bozarslan, "L'alévisme ou l'impossible équation du nationalisme en Turquie ", dans Riva Kastoryano, Alain Dieckhoff (dir.), Nationalismes en mutation en Méditerranée orientale, Paris, éditions du CNRS, 2002. 